outreach clinics. ${ }^{14}$ Pilot exchange schemes have now been set up in Liverpool, Peterborough, and elsewhere. What effect the exchange has had on HIV infection in Amsterdam is not known, but the system is now used by $30-50 \%$ of opiate injectors and does not appear to have increased the extent of injecting among addicts or the number of needle accidents $(R$ Coutinho, unpublished observations. The organisers point out, however, that the needle exchange is part of an overall "harm reduction" approach to addiction that seeks to minimise the risk to users who continue to inject. There is a consensus among medical and political authorities about this approach, and cooperation was negotiated with the police. At present these conditions do not generally prevail in Britain (Liverpool appears to be a notable exception). Proponents of needle exchanges may want to consider other approaches, including systems based on drug dependency units. Any needle exchange programme should be evaluated. The Italian experience suggests that needle availability alone will not control the epidemic.

Health education targeted at drug users currently consists of posters and leaflets in drug dependency units and voluntary agencies helping drug users. It may not reach the younger more inexperienced users who mav be most at risk. There is a need to make young drug users aware of what AIDS is like. Neither newspapers nor house to house distributions of leaflets are likely to reach this population, but television and radio probably will.

Finally, drug users could be tested to find those who are infected with HIV, and they could then be diverted into long term treatment, with the aim of minimising their use of needles and hence the likelihood of spread. A decision to test means providing long term medical and social care, as well as short term counselling, and runs into widespread fears about confidentiality and the management of infected drug users. The voluntary sector in particular is not convinced of the value of testing, but this approach will pay off where few users are infected and the potential for spread is large-as in Britain. American and Scottish experience suggests that most drug users will cooperate with voluntary testing if they are sure it is confidential, and where there is reluctance to provide needles a screening approach is another way of getting access to drug users.

There is no magic bullet for controlling the spread of HIV in drug users, and approaches must be tailored to local conditions. The Scottish report is right to recommend that local authorities should take charge of this second AIDS epidemic now. Developing consensus on giving out needles or using the antibody test will not be easy, but with the alarming potential for heterosexual transmission we should adopt Napoleon's motto: On s'engage et puis on voit.

Visiting Senior Research Fellow,

Academic Department of Genitourinary Medicine,

Middlesex Hospital Medical School,

London WIN 8AA

and

Adjunct Associate Professor,

Department of Epidemiology and International Health, University of California,

San Francisco 1 Scottish Home and Health Department. HIV Infection in Scotland. Edinburgh: SHHD, 1986. LAV) infection among intravenous drug users. Br Med f 1986;292:527-9.

3 Centers for Disease Control. Heterosexual transmission of human T-lymphotropic virus type IIV lymphadenopathy-associated virus. MMWR 1985;34:561-3.

4 Centers for Disease Control. Acquired Immunodeficiency Syndrome in Western Palm Beach County, Florida. MMWR 1986;35:609-12.

5 Chaisson R, Moss AR, Onishis R, Osmond MA, Carlson J. Human immunodeficiency virus infection in heterosexual drug users in San Francisco. Am $\mathcal{f}$ Publ Health (in press).
6 World Health Organisation Collaborating Center on AIDS. AIDS surveillance in Europe: situation by October 31 1986. Geneva: WHO, 1986.

7 Jesson WJ, Thorp RW, Mortimer PP, Oates JK. Prevalence of anti-HTLV-III in UK risk groups 1984/85. Lancet 1986;i:155.

8 Robertson JR. Drug users in contact with general practice. Br Med f 1985;290:34-5.

Webb G, Wells B, Morgan JR, McManus T. Epidemic of AIDS related virus infection among intravenous drug users. Br Med $\mathcal{F}$ 1986;292:1202.

10 DesJarlais DC, Friedman S, Hopkins W. Risk reduction for the acquired immunodeficiency syndrome among drug users. Ann Intern Med 1985;103:755-9.

11 The Drug Indicators Project. The drug situation in Greater London. London: Birkbeck College, 1986.

12 Pearson G, Gilman M, McIver S. Young people and heroin. London: Health Education Council, 1985. (HEC Research Report No 8.)

13 Hartnoll R, Mitcheson M, Lewis R, Bryer S. Estimating the prevalence of opioid dcependence. Lancet 1985; i:203-5.

14 Buning EC, Coutinho RA, van Brussel GHA, van Santen GW, van Zadelhof AW. Preventing AIDS in drug addicts in Amsterdam. Lancet 1986;ii: 1435.

\section{Treating postural hypotension}

When a person stands his cardiovascular system must maintain perfusion of the brain and support a column of blood equivalent to $150 \mathrm{~mm} \mathrm{Hg}$. The response depends critically on the integrity of the autonomic nervous system and adequate plasma volume. Falls of blood pressure greater than $10 \mathrm{~mm} \mathrm{Hg}$ are common on standing in the very elderly $^{12}$; in younger patients such falls are often caused by drugs (such as antihypertensive and psychotropic drugs, diuretics, levodopa, and alcohol) or diseases associated with depleted plasma volume (such as renal disease and Addison's disease). A few patients have chronic symptomatic orthostatic hypotension because of autonomic failure. ${ }^{3}$ Some patients have Parkinson's disease-either alone or associated with widespread brain stem and basal ganglia dysfunction leading to dysarthria, ataxia, and spasticity (multisystem atrophy or Shy-Drager syndrome). Others, who may present with a disturbance of the bowel, bladder, or sexual function, have progressive isolated failure of peripheral sympathetic nerve function; this may be primary or secondary to widespread peripheral neuropathy-as in diabetes mellitus or amyloidosis.

Cardiovascular sympathetic failure is best shown by recording intra-arterial blood pressure while a patient performs Valsalva's manoeuvre. ${ }^{4}$ In those with normal function blood pressure falls a little during blowing, but this is limited by tachycardia and peripheral vasoconstriction. Once the patient finishes blowing blood pressure rises above the original value, and then there is a reflex bradycardia. In contrast, patients with autonomic failure show a progressive fall in blood pressure during blowing with a slow return to the baseline and no overshoot or bradycardia after blowing. Impaired pressor responses to stress-for example, mental arithmetic, isometric exercise, or the cold pressor testmay be shown more simply with a sphygmomanometer. Impairment of parasympathetic control may be assessed by recording beat to beat heart rate responses to deep breathing and standing. ${ }^{5}$ The normal diurnal pattern of blood pressure -a fall of $10-20 \%$ at night during sleep ${ }^{6}$ is reversed in patients with autonomic failure-they often show a pronounced rise in supine blood pressure, ${ }^{7}$ which may lead the unwary to prescribe antihypertensive drugs.

Fluid and electrolyte homoeostasis is disturbed in patients with autonomic failure. They cannot concentrate urine during overnight recumbent dehydration or produce dilute urine during upright rehydration. ${ }^{8}$ This leads to a reversed diurnal pattern of urine excretion with nocturnal diuresis and natriuresis, extracellular fluid depletion, and a profound 
increase in orthostatic symptoms on rising in the morning. Symptoms often decrease during the day but may be exacerbated by eating as this may be followed by appreciable hypotension. ${ }^{9}$

Blood pressure in patients with autonomic failure is very sensitive to changes in extracellular fluid volume. Sleeping with the head and trunk raised $20^{\circ}$ reduces nocturnal diuresis and tends to restore fluid volume and reduce orthostatic symptoms. ${ }^{1011}$ This is the single most important measure in treating patients with autonomic failure-yet it is often ignored.

Drug treatment may be necessary if tilting the bed at night does not produce adequate improvement. When a doctor assesses a patient's response to drugs he must establish a stable baseline of sodium intake and be aware that orthostatic blood pressure responses may vary from day to day and are greatest on rising in the morning. He must also understand that loss of blood pressure buffering by baroreflexes, together with denervation hypersensitivity, may lead to dangerous pressor responses to drugs, particularly during recumbency.

Drugs that increase extracellular fluid volume are the first to use, and fludrocortisone is the drug of choice. ${ }^{12}$ It is introduced at a low dose $(0.1 \mathrm{mg} /$ day $)$ and titrated at intervals of 1-2 weeks; its effects are limited by fluid retention, supine hypertension, and hypokalaemia. If night tilt and fludrocortisone do not produce enough benefit then a cautious trial of indomethacin or other non-steroidal antiinflammatory drugs may be considered, ${ }^{1314}$ but they do not always help patients with autonomic failure. ${ }^{15}$ Treatment should be stopped if there is no objective evidence of benefit.

Drugs with $\alpha$ adrenergic agonist effects-for example, ephedrine and tyramine with a monoamine oxidase inhibitor - have been tried in patients with autonomic failure. ${ }^{16}$ They may, however, lead to pronounced hypertension, especially during recumbency. Furthermore, they often do not work and so have a very limited role in treatment. Drugs with $\beta$ adrenergic effects may be more useful. The number of $\beta$ adrenoceptors rises in autonomic failure, ${ }^{17}$ and $\beta$ adrenergic antagonists with intrinsic sympathomimetic activity-for example, pindolol-may have predominantly agonistic effects. ${ }^{18}$ The drugs do not always work, however, and heart failure has developed in some patients. ${ }^{19} 20$ Drugs with greater agonistic effects-for example, xamoterol, ${ }^{21}$ and prenalterol $^{22}$-may produce greater benefit with less risk of provoking heart failure, although these drugs have not yet been adequately assessed in sympathetic failure.

Recently two other modes of treatment have been investigated. Patients given intramuscular desmopressin (a vasopressin analogue) at night in a short term pilot study had less nocturnal diuresis and weight loss and an improved daytime blood pressure. ${ }^{23}$ Unfortunately one patient developed water intoxication. Long term studies using intranasal desmopressin will be necessary to show whether this drug is useful. Dihydroergotamine is a synthetic ergot alkaloid with venoconstrictor effects that has been well tolerated when used to prevent perioperative venous thrombosis. ${ }^{24} 25$ It improved daytime blood pressure when given intramuscularly to patients with orthostatic hypotension secondary to diabetes or alcoholism. ${ }^{26}$ Postprandial hypotension remained troublesome but was much improved by combined treatment with dihydroergotamine and caffeine ( $250 \mathrm{mg}$ before breakfast). Further studies will be necessary to show whether this combination is useful in patients with primary autonomic failure and whether supine hypertension will limit its usefulness.
The cornerstone of treating patients with autonomic failure is tilting the bed at night and volume expansion with fludrocortisone. In patients disabled by persisting orthostatic symptoms other forms of treatment may be considered-but they require very careful assessment because of serious side effects.

Consultant Cardiologist,

R D S WATSON

Dudley Road Hospital,

Birmingham B18 7QH

1 Johnson RH, Smith AC, Spalding JMK, Wollner L. Effect of posture on blood pressure in elderly patients. Lancet 1965;i:731-3.

2 Caird FI, Andrews GR, Kennedy RD. Effect of posture on blood pressure in the elderly. Br Hear f 1973;35:527-30.

3 Bannister R. Clinical features of progressive autonomic failure. In: Bannister R, ed. Autonomic failure. A textbook of clinical disorders of the autonomic nervous system. Oxford: Oxford Medical Publications, 1983:67-73.

4 Bannister R, Sever P, Gross $M$. Cardiovascular reflexes and biochemical responses in progressive autonomic failure. Brain 1977;100:327-44.

Wheeler TT, Watkins PJ. Cardiac denervation in diabetes. Br Med F 1973;iv:584-6.

6 Littler WA, Honour AJ, Carter RD, Sleight P. Sleep and blood pressure. BrMed I 1975; iii:346-8.

6 Littler WA, Honour AJ, Carter RD, Sleight P. Sleep and blood pressure. Br Med $\mathcal{f} 1975 ;$ iii: $346-8$.
7 Mann S, Altman DG, Raftery EB, Bannister R. Circadian variation in blood pressure in Mann S, Altman DG, Raftery EB, Bannister
autonomic failure. Circulation 1983;68:477-83.

8 Wilcox CS, Aminoff MJ, Penn W. Basis of nocturnal polyuria in patients with autonomic failure. I Neurol Neurosurg Psychiatry 1974;37:677-84.

9 Robertson D, Wade D, Robertson RM. Postprandial alterations in cardiovascular haemodynamics in autonomic dysfunction states. Am f Cardiol 1981;48:1048-52.

10 Maclean AR, Allen EV. Orthostatic hypotension and orthostatic tachycardia. Treatment with "head-up" tilt. JAMA 1940;115:2162-7.

11 Bannister R, Ardill L, Fentem P. An assessment of various methods of treatment of idiopathic orthostatic hypotension. $Q \mathcal{H}$ Med 1969;38:377-95.

12 Davies B, Bannister R, Sever PS, Wilcox CS. The pressor actions of noradrenaline, angiotensin II and saralasin in chronic autonomic failure treated with fludrocortisone. Br f Clin Pharmacol and saralasin in $1979 ; 8: 253-60$.

13 Kochar MS, Itskovitz HD. Treatment of idiopathic orthostatic hypotension (Shy-Drager syndrome) with indomethacin. Lancet 1978;i:1011-4.

14 Watt SJ, Toole JE, Perkins CM, Lee $M$. The treatment of idiopathic orthostatic hypotension: a combined fludrocortisone-flurbiprofen regime. $Q \mathcal{F}$ Med 1981;50:205-12.

15 Davies IB, Bannister R, Hensby C, Sever PS. The pressor actions of noradrenaline and angiotension II in chronic autonomic failure treated with indomethacin. $\mathrm{Br} \mathcal{F}$ Pharmacol 1980;10:223-9.

16 Davies B, Bannister R, Sever P. Pressor amines and monoamine-oxidase inhibitors for treatment of postural hypotension-limitations and hazards. Lancet 1978;i:172-5.

17 Bannister R, Boyston AW, Davies IB, Matthias CJ, Sever PS, Sudera D. Beta receptor numbers and thermodynamics in denervation hypersensitivity. I Physiol (Lond) 1981;319:369-77.

18 Man in't Veld AJ, Schalekamp MADH. Pindolol acts as beta-adrenoceptor agonist in orthostatic hypotension; therapeutic implications. Br Med $\mathcal{J}$ 1981;282:929-31.

19 Davidson AC, Smith SE. Pindolol in orthostatic hypotension. Br Med f 1981;282:1704.

19 Davidson AC, Smith SE. Pindolol in orthostatic hypotension. Br Med f 1981;282:1704.
20 Davies B, Bannister R, Mathias C, Sever P. Pindolol in postural hypotension: the case for caution. Lancet $1981 ;$ ii: $982-3$.

21 Mehlsen J, Trap-Jensen J. Xamoterol, a new selective $\beta$-1-adrenoceptor partial agonist, in the treatment of postural hypotension. Acta Med Scand 1986;219:173-7.

22 Goovaerts J, Verfaillie C, Fagard RR, Knockaert D. Effect of prenalterol on orthostatic hypotension in Shy-Drager syndrome. Br Med f 1984;288:817-8.

23 Mathias CJ, Fosbraey P, da Costa DF, Thornley A, Bannister R. The effect of desmopressin on nocturnal polyuria, overnight weight loss, and morning postural hypotension in patients with autonomic failure. BrMed I 1986;293:353-5.

24 Morris WT, Hardy AE. The effect of dihydroergotamine and heparin on the incidence of thromboembolic complications following total hip replacement: a randomized controlled clinical trial. Brf Surg 1981;68:301-3.

25 Sasahara AA. Dihydroergotamine-heparin prophylaxis of postoperative deep vein thrombosis. 7AMA 1984;257:2960-66.

26 Hoeldtke RD, Cavanaugh ST, Hughes JD, Polansky M. Treatment of orthostatic hypotension with dihydroergotamine and caffeine. Ann Intern Med 1986;105:168-73.

\section{Enuresis at 25}

Recently I heard of an elderly woman whose son had been a bedwetter for 30 years. She had been completely unaware of continence services-for her the plastic mattress cover was one of the wonders of modern science. Adults with enuresis are not rare, and, although some can be successfully treated, others need the support of continence services.

Enuresis is a normal reflex act of micturition during sleep and is thus different from the overflow incontinence at night that might be the presenting symptom of chronic retention of urine. Why the detrusor muscle involuntarily contracts in patients with enuresis is not known, but it may be an impairment of either sensory perception or motor inhibition. 